\title{
Editorial - The use and abuse of risk management
}

Slowly, slowly, the practice of risk management is infiltrating the mainstream of institutional portfolio management. Lip service to risk management has been well established for over a decade, of course, but spurred on by a combination of high-profile lawsuits, the worst bear market for a generation, and just a pinch of healthy competition, most institutional investment firms now have at least a Risk and Performance Group, if not a real, live Risk Monitoring Department.

There is, of course, nothing like a really good bear market to get fund managers reaching for their risk analyses. Indeed, the first wave of widespread acceptance of risk models in the London market can be dated back to the two quarters after the October 1987 crash.

At the time of writing, the Third Annual Risk Management Conference is fast approaching, and promises to become an established feature of the conference circuit. Hedge fund risk management is the current hot topic that everyone wants to hear about. Even the consultants are getting in on the act, advising their pension fund clients on risk budgeting.

While it is certainly a good thing that risk management is becoming more important in institutional investment, some of the ways in which it is currently being applied are more than a little disquieting.

In particular, the notion that risk monitoring is something that is only done to a portfolio well after the manager has finished putting it together clearly falls some way short of Harry Markowitz's idea that risk and expected return should be taken into account together when rebalancing a portfolio. It is widely recognised that very few managers actually select stocks for a portfolio on the basis of (quantified) expected return forecasts, but are much more likely to have a variety of qualitative assessments of their prospects. Nonetheless, it should surely be possible to bring the introduction of risk management techniques a little closer to the portfolio rebalancing process than mere ex post risk monitoring by a different department, who will only feed the results back to the manager if some stipulated guidelines are breached. This does not sound much like trading-off risk against expected return uniformly throughout the portfolio. The notion of portfolio efficiency seems to have been lost in the translation from theory into practice.

Risk budgeting is another example of a little knowledge being a dangerous thing. It is hard to pin down exactly, but risk budgeting seems to refer to the idea that a pension fund might have a certain overall amount of risk that they would be willing to accept in seeking higher returns than a strict liability-matching asset allocation. The issue that then arises is how this 'risk budget' should be allocated across a number of different managers in different asset categories. The details of how this is done do not 
matter: the flaw in the concept lies in the implicit assumption that the overall risk decomposition of any given asset allocation can be determined uniquely. This is only true in a limited number of cases. If we have allocated our assets to half-a-dozen managers, however, and know what our overall tracking error is relative to a strategic asset allocation, we cannot easily answer the question 'How much of the risk is coming from our assets with Manager X?' In fact, it turns out that there are at least three, and possibly an infinite number of answers to this innocuous-sounding question.

While the infiltration of risk management into institutional fund management is a positive step, consultants and practitioners still have some way to go to develop risk management techniques that are both useful in a practical sense, and theoretically and conceptually rigorous. As the finance academics are so fond of saying, 'More work is needed'.

Jason MacQueen Chairman, Alpha Strategies LLC and Senior Consultant, Thomson Financial, UK Editorial Board September 2002 